\title{
Os óculos latino-americanos e o monóculo europeu: Manuel Bandeira e Eça de Queirós
}

\author{
ElZa Miné \\ (Universidade de São Paulo / CNPq)
}

RESUMO: O POETA MANUEL BANDEIRA FOI O PRIMEIRO A FAZER O LEVANTAMENTO (TÍTULOS E DATAS) DOS TEXTOS PUBLICADOS POR EÇA DE QUEIRÓS NA GAZETA DE NOTÍCIAS DO RIO DE JANEIRO, DE 1880 A 1897, ACOMPANHANDO-O DE ALGUNS COMENTÁRIOS. O PRESENTE TEXTO FOCALIZA A CONTUNDENTE REAÇÃO CRÍTICA DO POETA A UM CONJUNTO DE MATÉRIAS DE EÇA ALI PUBLICADAS QUATRO ANOS ANTES DE SUA MORTE, SOB O TÍTULO GERAL DE "A PROPÓSITO DA DOUTRINA DE MONROE E DO NATIVISMO".

ABSTRACT: THE BRAZILIAN POET MANUEL BANDEIRA WAS THE FIRST INTELLECTUAL TO MAKE A SURVEY (OF TITLES AND DATES) OF EÇA DE QUEIRÓS' TEXTS PUBLISHED ON THE GAZETA DE NOTÍCIAS (RIO DE JANEIRO, BRAZIL) FROM 1880 TO 1897, TO WHICH HE'S ATTACHED SOME COMMENTS. THIS TEXT FOCUSES ON THE POET'S CONTUSIVE CRITICAL REACTION TO A GROUP OF EÇA'S TEXTS PUBLISHED ON THAT NEWSPAPER FOUR YEARS BEFORE HIS DEATH, UNDER THE GENERAL TITLE OF “A PROPÓSITO DA DOUTRINA DE MONROE E DO NATIVISMO" ("ON MONROE DOCTRINE AND NATIVISM").

PALAVRAS-CHAVE: EÇA DE QUEIRÓS - MANUEL BANDEIRA - IMPRENSA BRASILEIRA NO SÉCULO XIX - DOUTRINA DE MONROE - NATIVISMO.

KEY-WORDS: EÇA DE QUEIRÓS - MANUEL BANDEIRA - BRAZILIAN PRESS IN THE 19TH CENTURY - MONROE DOCTRINE - NATIVISM. 
sabido que no século XIX, principalmente a partir do Romantismo, estiveram muito em voga e foram largamente produzidos os livros de viagem. Vinham satisfazer a curiosidade por outras paisagens, outros povos, outras culturas, curiosidade esta despertada e alimentada pelo alargamento progressivo de horizontes.

Se hoje a globalização midiática institui e redimensiona diferentes formas de aproximação e construção mútua de imagens, ao tempo de Eça de Queirós, para que se processasse alguma interação desse tipo, ou ocorria o contato direto com novos contextos, através de viagens, ou então, jornais e revistas, muitas delas ilustradas, davam a ler/ver imagens do "outro", imagens estas, por sua vez, resultado de olhares e representações, quer livrescamente construídas, quer decorrentes da experiência concreta de ir-se "pela terra alheia" ( para lançarmos mão de um título de Ramalho Ortigão).

A interferência de conhecimentos prévios, de estereótipos, de experiências anteriores - agradáveis ou não - do viajante/cronista com o novo espaço, seu pendor para a ficcionalização, em maior, menor, ou nenhum grau, seus credos políticos ou religiosos, tudo concorria e, de certa forma, direcionava esses confrontos de identidades.

Centrando-me em textos de imprensa enviados por Eça de Queirós para a Gazeta de Notícias do Rio de Janeiro, mais especificamente nas matérias publicadas nos dias 30 e 31 de março e 1 a 5 de abril de 1896, mas recorrendo ainda à correspondência e a relatórios consulares, pretendo observar como o característico monóculo crítico de Eça assenta sobre o "outro", o do Novo Mundo, construindo imagens e tecendo considerações avaliativas. Ao mesmo tempo, tenho em vista considerar como os inseparáveis óculos de grossas lentes corretoras de Manuel Bandeira lêem e discutem as imagens projetadas e as posições expostas pelo correspondente daquele jornal carioca.

Começo por lembrar que, tendo Eça de Queirós feito o concurso para a carreira diplomática (na mesma ocasião em que também se apresentou como candidato seu amigo e companheiro dos tempos da Travessa do Guarda-Mor, Jaime Batalha Reis), foi em Havana que teve o seu primeiro posto consular, para depois servir na Inglaterra (Newcastle e Bristol) durante 14 anos e terminar a carreira em Paris, onde permaneceu até sua morte, em 1900.

O período caribenho estendeu-se de 1872 a 1874. Mas, preocupado com o clima de Cuba e com sua saúde, passou parte do tempo fora da ilha (julho 
a novembro de 73), viajando nos Estados Unidos e no Canadá. Em carta a Ramalho Ortigão, escrita de Havana, em 1873, diria:

o que não estou é condescendente com esta terra estúpida para onde vim, embrulhado num decreto, impelido por um tratado. Oh! A estúpida, feia, suja, odiosa, ignóbil cidade. Oh! A grosseira gente! Oh! As ridículas calças que usam! Oh! A infecta prosa dos jornais! Oh! O ar de suor que tudo tem! - Ah! Meu amigo, esta cidade, esta gloriosa e ardente e pálida terra das cantigas de zarzuela - que miserável aldeia é, com todos os seus palácios, com todos os seus trens puxados a 4 cavalos cobertos de prata! Ah! A miserável, subalterna, rasteira maneira destes espíritos! Ah! As mesquinhas preocupações destes sentimentos! Ah! O terrível preço de uma camisa! Ah! o mau vinho! E os sujos hotéis! E as pintadas mulheres! Detesto-a, esta cidade esverdeada e milionária, sombria e ruidosa - este depósito de tabaco, este charco de suor, este estúpido paliteiro de palmeiras! Ah! Meu amigo - quem me dera a Rua dos Caetanos! (QUEIRÓS, 1983: 74-75)

Durante seu tempo de serviço consular em Cuba, aí ocorriam, de um lado, a importação de trabalhadores chineses, contratados em Macau, para suplementar a mão-de-obra escrava nas plantações de cana de açúcar e, de outro, a insurreição nacionalista contra o domínio espanhol, começada em 1868, e que viria a ser conhecida como a Guerra dos Dez Anos, a que Eça parece ter dado bem menos atenção - quer nos relatórios consulares, quer em sua correspondência particular e consular - do que à questão dos coolies chineses. ${ }^{1}$

Anos mais tarde, no início de dezembro de 1894 (dias 1, 2, 3, 5 e 6), Eça publicaria na Gazeta uma longa matéria a propósito do conflito sino-japonês de 1894-95. O terço final desta longa matéria focaliza a imigração chinesa em Cuba, nessa mesma Cuba em que "sóis tórridos, chuvas trespassantes, terrenos paludosos, micróbios e toxinas não têm ação sobre aquele ser, de aparên-

1 A imigração chinesa vê-se tratada em quatro cartas consulares, completando-se com a parte final do relatório publicado com o título $A$ emigraşão como força civiliząadora, como já no prefácio nos chama atenção Alan Freeland que competente e criteriosamente publicou, em 1994, a Correspondência Consular de Eça (cf. QUEIRÓs, 1994). 
cia mole e como feito de borracha [o chinês]." (QUEIRÓS, 2002: 527-546). ${ }^{2}$

$\mathrm{E}$ foi naqueles anos cubanos que bem vivenciara a situação de estar diante do "outro", de "outros" no Novo Mundo, em relação aos quais pode melhor sentir-se europeu. A carta a Ramalho Ortigão, também de 1873, é mais do que explícita e esse respeito:

Estou longe da arte e portanto longe da serenidade e do contentamento. Saí da minha atmosfera e vivo inquieto, num ar que não é o meu. Além disso, estou longe da Europa e você sabe quão profundamente somos europeus, você e eu. Isto aqui - ou pelo seu mau lado espanhol, ou pelo seu curioso feitio americano (dos Estados Unidos), é muito diferente. Eu preciso de política, crítica, corrupção literária, humorismo, estilo, colorido, palheta; aqui, estou metido num hotel, e quando discuto, é sobre câmbios - e quando penso, é sobre coolies. (QUEIRÓS, 1983: 71)

Corroborando tal afirmação, o conjunto de colaborações para o Rio de Janeiro, exibe, sempre, posições inequivocamente eurocêntricas, como já procurei mostrar noutro lugar.

\section{Mapeando os textos queirosianos da Gazeta de Notícias}

Reportemo-nos agora a 1945, ano do primeiro centenário do nascimento de Eça. Entre as muitas comemorações registradas, uma iniciativa se destaca, pela importância das contribuições que enfeixa: trata-se do Livro do Centenário, organizado por Lúcia Miguel Pereira e Câmara Reis (QUEIRÓS, 1945).

É neste volume que aparecem duas colaborações que de perto nos interessam: a do nosso poeta Manuel Bandeira, "Correspondência de Eça de Queirós para a imprensa brasileira", e a de Raimundo Lago, "Eça y Cuba" (QUEIRÓS, 1945: 167-182 e 365-375).

Vamos nos ocupar apenas de Bandeira, não sem antes assinalar que ambos os artigos acima mencionados, focalizando praticamente os mesmos textos

2 A matéria, como um todo, " revela mais sobre a civilização ocidental e sua história, em particular sobre o pensamento de Eça de Queirós como 'português estrangeirado', do que sobre uma visão das culturas da China e do Japão.” (QUEIRÓS, 1997: 9-10). 
jornalísticos queirosianos com os quais diretamente dialogam, testemunham a recepção crítica de dois latino-americanos a matérias que diretamente nos dizem respeito.

Em seu artigo, nosso grande poeta apresenta, pioneiramente, o mapeamento de datas e títulos das matérias de Eça publicadas na Gazeta de Notícias, de 1880 a 1897. Desse levantamento diretamente se serviu Guerra da Cal, na sua monumental Bibliografia Queirociana e também nós, Neuma Cavalcante e eu, na preparação da edição crítica de tais textos de imprensa enviados para o Brasil, no âmbito do projeto da edição crítica da obra do autor: Textos de imprensa IV (da Gazeta de Notícias).

Manuel Bandeira, nos comentários que acompanham seu levantamento, detém-se, particularmente, nos textos publicados em 30 e 31 de março e 1 a 5 de abril de 1896, com o título - "A doutrina de Monroe e o nativismo". O extenso artigo de Eça que se volta para a referida doutrina e, em seguida, e mais longamente, apresenta como seu desdobramento - o nativismo - tem como elemento deflagrador (como muito freqüentemente ocorre em seus textos jornalísticos) a consideração de um fato ou questão da atualidade para daí expandir-se em interpretações de caráter mais geral que não prescindem de retrospectos históricos e projeções futuras para melhor enquadramento do ponto focado, estratégias essas que servem sempre a propósitos persuasivos do jornalista, com vistas à busca de adesão do leitor para seus pontos de vista. No caso, é o conflito anglo-americano, segundo diz, por "algumas milhas de terra perdidas na Venezuela" que se vê focalizado.

Antes de examinarmos como Bandeira comenta esta matéria, alguns dados rápidos sobre tal "doutrina".

\section{Rememorando a doutrina de Monroe}

James Monroe, presidente dos Estados Unidos (1816-1824), em mensagem enviada ao Congresso no dia 2 de dezembro de 1823 , reiterava a neutralidade dos Estados Unidos na guerra entre a Espanha e suas colônias, tendo embora como certo que ela jamais poderia reconquistá-las. A mensagem de Monroe, ajudando Canning a enterrar os planos de recolonização da Santa Aliança, declarava essencialmente que se proibia a qualquer estado europeu 
estabelecer colônias no Novo Mundo e intervir nas questões americanas: "A América para os americanos".

No entanto, em publicação de 1973, Moniz Bandeira explicita:

A declaração de Monroe traduzia uma posição exclusivamente nacional, hegemônica, conquanto ainda sem amparo mas assentando as bases do sistema de ficções doutrinárias que justificaria, concretamente, a expansão e depois o domínio do capitalismo americano. (BANDEIRA, 1973: 50)

Já muito antes, Eduardo Prado em A ilusão americana, de 1893, cuja edição foi apreendida, no Brasil, havia realizado o primeiro protesto contra a alienação do país: "A amizade americana é nula, quando não é interesseira". À denúncia de Prado, seguira-se a de Joaquim Nabuco, que posteriormente aderiu à República, defendeu o pan-americanismo e foi o primeiro embaixador brasileiro em Washington. Oliveira Lima, no entanto, não concordava com Eduardo Prado que, por ele considerado "um panfletário de grande talento", condenava in limine toda a civilização americana. Mas reconheceu que os Estados Unidos realmente se encaminhavam para o imperialismo e se tornariam uma grande potência colonial. Em 1907, mostraria Oliveira Lima em Pan-americanismo maiores reservas diante dos Estados Unidos, especialmente com relação à Doutrina de Monroe. Já em 1906, na Terceira Conferência Pan-americana, assim se manifestara: “É força dizer que a Doutrina Monroe só veda conquista da América aos europeus, não a veda aos americanos-donorte, pelo menos enquanto for exclusiva a doutrina".

Nesse longo texto queirosiano, "A doutrina de Monroe e o nativismo", Manuel Bandeira, além de se defrontar com a introdução já tantas vezes comentada sobre o rastaquerismo sul-americano, se depara com afirmações tais como: "A América pertence exclusivamente aos europeus que nasceram na América" porque o americano, no puro sentido etnológico, praticamente não existe. $\mathrm{E}$ para ver este "espécime venerável dos velhos senhores do solo" seria preciso ir para além do país dos búfalos, pois, só “aí será possível, em torno a alguma estação do caminho de ferro do Pacífico, avistar um 'americano', cor de cobre, de longas guedelhas corredias, mirrado e embrutecido" (BANDEIRA, 1973: 94).

E Eça insiste, veementemente, na cobrança dos "créditos" da Europa em face da América: 
Essa América, que tanto se ufana de gênio inventivo, nada inventou nestes últimos trezentos anos, que têm sido os mais fecundamente ativos da humanidade. E fomos nós, aqui nesta esfalfada Europa, que, suando e gemendo, continuamos a espantosa tarefa da civilização, descobrindo as leis universais, criando as ciências naturais, construindo os sistemas de filosofia, apurando a beleza das artes, fundando indústrias, dando ao mundo a imprensa, a eletricidade, o gás, o vapor, os teares, os telégrafos, milhões de livros, toda a sorte de idéias!...

E destes benefícios inumeráveis, recebidos pelas naus da carreira, logo a boa América se utilizava e gozava, conspirando já, surdamente, contra a nossa supremacia. O motivo que ela invocava para esta sua soturna abstenção na obra humana do Progresso era que o seu gênio estava sufocado sob a dureza do regime colonial. (BANDEIRA, 1973: 598)

Assim apresentada a América, naturalmente o nativismo, "filho bastardo e petulante" da doutrina Monroe, só poderia ser considerado uma escandalosa e inadmissível "ingratidão". Em pares contrastivos, o americano e o europeu vêem-se, respectivamente, caracterizados como: indolente/laborioso; obtuso/inteligente; fraco/forte e "nativistas" nada mais seriam do que aqueles que haviam falhado em vista do estrangeiro que acertara.

A reação contundente de Bandeira

Depois de ressaltar a justeza com que Eça havia considerado, em seus artigos, a França e a Inglaterra, afirma o poeta:

Não guardou, porém, a mesma isenção em face do Novo Mundo. Jamais compreendeu a evolução histórica, os problemas políticos e sociais da América. A esta olhou sempre com os piores prejuízos do europeu metropolitano. Compreende-se que a subestimasse nos tempos do consulado de Havana, quando era moço e andava arrealiado com o calor tropical, o desconforto dos hotéis, as saudades da Rua dos Caetanos e a questão dos chins. Mas quatro anos antes de morrer, no ensaio sobre a doutrina de Monroe, insiste em argumentos ignaros e da mais clamorosa injustiça. O imenso drama da organização política americana, a que tantos homens de incomparável nobreza sacrificaram a vida, só se lhe antolhava como 'uma bela pândega anárquica'. Via em nossos melindres de autonomia 'o surdo despeito que os povos coloniais conservam contra os seus antigos dominadores, cuja civilização mais requintada, por ser a mais velha e 
mais complexa, eles nunca podem igualar na sua beleza, estabilidade e brilho histórico'.

Ousa dizer, na sua leviana ignorância, que jamais concorremos, os americanos, para a obra da civilização do mundo 'com uma idéia nova, nem com uma forma nova'. Não tomou conhecimento dos Irvings, dos Emersons, dos Thoreaus, dos Hawthornes, dos Melvilles, dos Martis, dos Hostos, dos Bellos, dos Sarmientos. Eça esteve em Havana e nos Estados Unidos em 73. A terceira edição das Leaves of Grass data de 60: o gênio profundamente original e renovador de Whitmann passou-lhe despercebido. E para desmentir, tão gloriosamente para a América, o juízo do europeu filaucioso, ainda em vida do Eça um pobre mestiço de Nicarágua, sem instrução regular e formado ao acaso de suas leituras de autodidata, ia renovar surpreendentemente as fontes de poesia da língua espanhola. ${ }^{3}$

$\mathrm{Na}$ reação vigorosa de Bandeira, que se volta contra o desconhecimento e a incompreensão queirosianos, não há modalizações contemporizadoras: "jamais compreendeu"; "piores juízos"; "argumentos ignaros"; "clamorosa injustiça"; "leviana ignorância"; "se lhe antolhava" - a mais forte das expressões usadas por figurativamente designar 'visão ou compreensão limitada, observação de apenas um lado da questão', mas provir de 'antolhos', ou seja,'viseira', duas peças de couro colocadas sobretudo em alguns animais de tração.

Com igual contundência, os óculos latino-americanos, de grossas lentes corretoras, assestam agora suas baterias contra o provocador monóculo europeu... Aos primeiros, nem mesmo falta a pincelada irônica - "melindres de autonomia" - tão ao modo e ao gosto do segundo...

A veemência do revide de Bandeira, sobretudo aos ataques de Eça ao nativismo, se explica e se justifica. Tal crítica, bem como a longa matéria que a suscita, merecem um exame mais demorado, que deixamos para outra oportunidade.

3 Trata-se, acredito, de Rubén Darío (1867-1960), nascido em Metapa, na Nicarágua. Manuel Bandeira em seu livro Literatura hispano-americana, assim diz: "Hay em mi sangre alguna gota de sangre de África, o de indio chorotega? Pudiera ser, a despecho de mis manos de marqués. Essas palavras do prefácio das Prosas profanas e a sua mesma fisionomia de pronunciado tipo mongólico inculcam-no como mestiço" (BANDEIRA, 1960: 159). Eça morreu em 1900 e Bandeira afirma ainda que Darío já era famoso em 1888, data também em que já era evidente seu papel de renovador da poesia hispânica (BANDEIRA, 1960: 160). 
Por ora, no entanto, seria importante não esquecer as diferentes imagens e avaliações encontráveis nos dois textos, segundo a origem geográfica do enunciador. E também lembrar a perspectiva captada (e asseverada) pelas antenas do observador europeu: a doutrina de Monroe "já não constitui uma defesa contra a preponderância da Europa, na livre América, mas estabelece um verdadeiro princípio de agressão contra a autonomia das repúblicas américo-latinas".

O resto da história, todos nós conhecemos...

\section{Referências Bibliográficas}

BANDEIRA, Manuel. Literatura Hispano-Americana. 2. ed. Rio de Janeiro: Fundo de Cultura, 1960.

BANDEIRA, Moniz. Presença dos Estados Unidos no Brasil: dois séculos de história. Rio de Janeiro: Civilização Brasileira, 1973.

QUEIRÓS, Eça de. Correspondência, v. 1. Leit. ,coord., pref. e notas de Guilherme de Castilho. Lisboa: Imprensa Nacional/Casa da Moeda, 1983. . Correspondência Consular. Ed. Alan Freeland. Lisboa: Edições Cosmos, 1994. Chineses e Japoneses. Prefácio de Orlando Grossegesse. Lisboa: Cotovia/Fundação Oriente, 1997. Chineses e Japoneses. In: Textos de Imprensa IV. Lisboa: Imprensa Nacional/ Casa da Moeda, 2002. . Livro do Centenário de Eça de Queirós. Ed. Lúcia Miguel Pereira e Câmara Reis. Lisboa: Rio de Janeiro: Dois Mundos, 1945. 